\title{
Extending the fatigue service life of a railway bridge by local approaches
}

\begin{tabular}{|r|l|}
\hline Journal: & IABSE Spring Conference 2013 \\
\hline Manuscript ID: & RTM-0127-2013.R1 \\
\hline Theme: & Load carrying capacity and remaining lifetime \\
\hline Date Submitted by the Author: & $\mathrm{n} / \mathrm{a}$ \\
\hline Complete List of Authors: & $\begin{array}{l}\text { Andersson, Andreas; KTH Royal Institute of Technology, Department of } \\
\text { Civil and Architectural Engineering } \\
\text { Leander, John; KTH Royal Institute of Technology, Department of Civil and } \\
\text { Architectural Engineering } \\
\text { Karoumi, Raid; KTH Royal Institute of Technology, Department of Civil and } \\
\text { Architechtural Engineering }\end{array}$ \\
\hline Type of Structure: & Bridges \\
\hline Material and Equipment: & Steel \\
\hline Other Aspects: & Fatigue, Instrumentation / Monitoring, Assessment / Repair \\
\hline
\end{tabular}

\section{SCHOLARONE ${ }^{m}$ \\ Manuscripts}




\title{
Extending the fatigue service life of a railway bridge by local approaches
}

\author{
Andreas ANDERSSON \\ $\mathrm{PhD}$, Researcher \\ KTH Royal Institute of \\ technology (KTH), Stockholm, \\ Sweden adde@kth.se \\ John LEANDER \\ Lic. Engr. (KTH) \\ Raid KAROUMI \\ $\mathrm{PhD}$, Prof. (KTH)
}

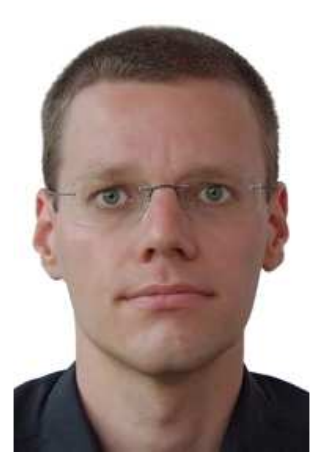

\begin{abstract}
Andreas Andersson, born 1980, received his MSc in Civil Engineering in 2004, Lic Engr. in 2009 and PhD in 2011, all from $\mathrm{KTH}$. He works as an engineer at the Swedish Transport Administration and as a researcher at KTH. His main research areas involve capacity assessment, fatigue assessment and dynamics of bridges using numerical methods and field measurements.
\end{abstract}

\section{Summary}

In this paper, fatigue assessment of a steel railway bridge is presented. The bridge is located in central Stockholm, Sweden, and is one of the most vital links for the railway network. The bridge services both freight trains and commuter trains with more than 500 passages per day. The main load bearing structure is designed as a steel grillage of welded I-beams. Fatigue critical sections have been identified at locations where secondary bracing systems are welded to the flanges of the I-beams. Both numerical simulations and extensive field measurements have shown a significant exceedance of the theoretical fatigue service life. Based on analysis of local stress concentrations, improvement of fatigue critical details have been suggested. The decrease in stress concentration is demonstrated both by numerical simulations and in-situ field measurements and shows a significant improvement when estimating the remaining fatigue service life.

Key words: cumulative fatigue damage; railway bridge; hotspot stress; finite element method.

\section{Introduction}

Fatigue assessment of existing railway bridges is often performed similarly to new bridges, by comparing a design stress range with the design fatigue strength. A more comprehensive procedure for fatigue assessments can be found in [4]. The fatigue strength is usually determined based on a detail category for nominal stresses and a prescribed number of stress cycles. If the allowable utilization is exceeded, more detailed assessments may be called for. A more realistic stress collective can be estimated by simulation of real trains and cycle counting, or optionally in combination with field measurements. Still, some bridges may fail to provide a sufficient remaining fatigue life. For cases of high stress concentrations, methods based on local approaches can be useful, both to determine the rate of cumulative damage and in suggesting detail improvement.

\section{Case study bridge}

A case study of the Söderström railway bridge is presented. The bridge carries two railway tracks between Riddarholmen and Söder Mälarstrand in central Stockholm, Sweden. A view of the bridge is seen in Fig. 1. The bridge constitutes the only South railway passage to Stockholm Central station and an average of more than 500 trains pass the bridge every day. The bridge has been in service since 1950. During routine inspections, fatigue cracks in main beam - to web stiffener connections were found and an extensive capacity assessment of the bridge was initiated. The observed fatigue cracks were later repaired, however, the capacity assessment identified other fatigue critical connections [1]. A field measurement campaign was performed, partly verifying the theoretical estimates [5-8]. Geometrical improvement of the most critical connections have been proposed, showing a potential improvement of the fatigue service life when assessed with local stress methods, further to be presented in this paper. 


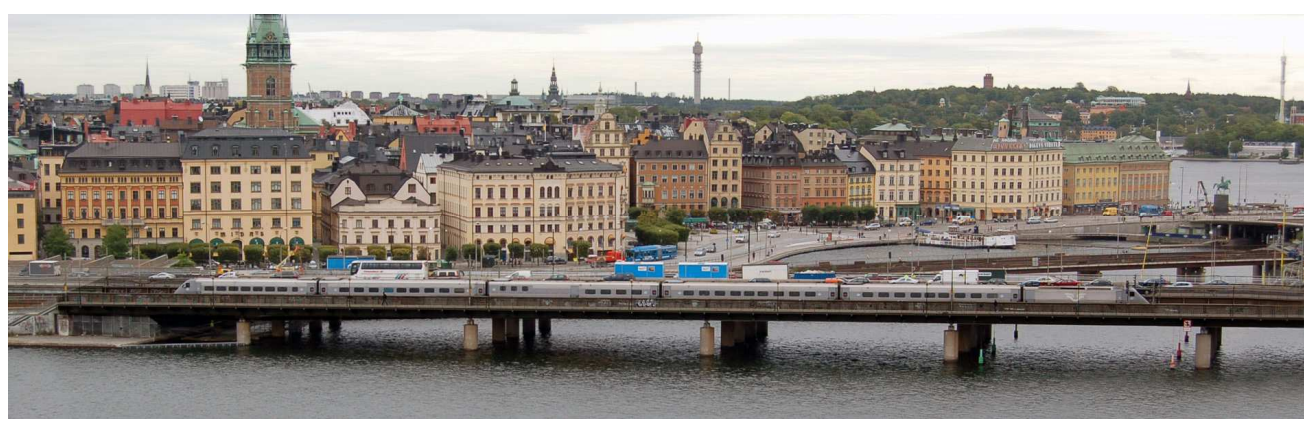

Fig. 1: View of the Söderström railway bridge during passage of a long distance train X2.

\subsection{Bridge properties}

The bridge is designed as a six-span continuous steel grillage, carrying two railway tracks. The outer spans are $27 \mathrm{~m}$ and the inner spans $33.7 \mathrm{~m}$, Fig. 2. The tracks are supported by wooden sleepers, resting directly on the stringers, Fig. 3. The stringers are continuous and welded to the cross beams. The distance between the cross beams is $3.4 \mathrm{~m}$. The bridge is skewed in the horizontal plane by an angle of $10^{\circ}$.

Secondary bracing systems connects between the lower flange of the cross beams and the main beams as well as to the upper flanges of the stringers. All flange to bracing connections consist of transverse gusset plates, welded to the flange without any noticeable radius. These connections are found at more than 450 positions on the stringers, 100 positions on the main beams and 50 positions on the cross beams. The main concern is the fatigue service life of the stringers due to these connections.

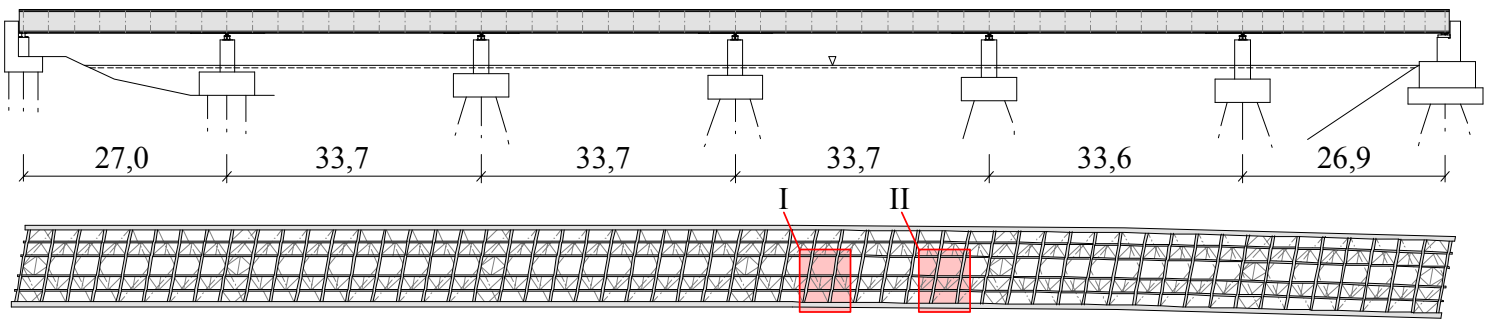

Fig. 2: Elevation and plan view of the Söderström railway bridge.
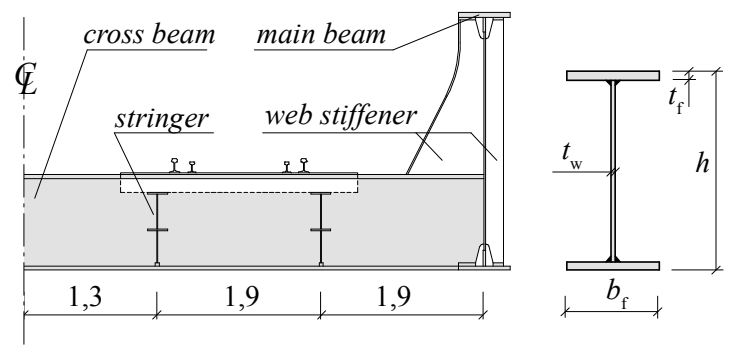

Table 1: Geometry of the I-beams.

Fig. 3: Cross-section of the grillage, symmetric half section of one track.

\subsection{Instrumentation}

A total of 54 strain gauges were instrumented at fatigue critical sections on the bridge. The full instrumentation can be found in [1] and [5]. In 2011, some gauges were repositioned to measure local stress concentrations near the transverse gusset plates. The instrumentation is presented in Fig. 4, the location of the instrumented sections are indicated in Fig. 2. 


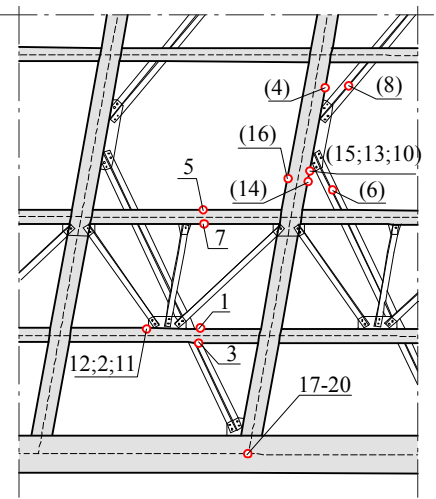

a)

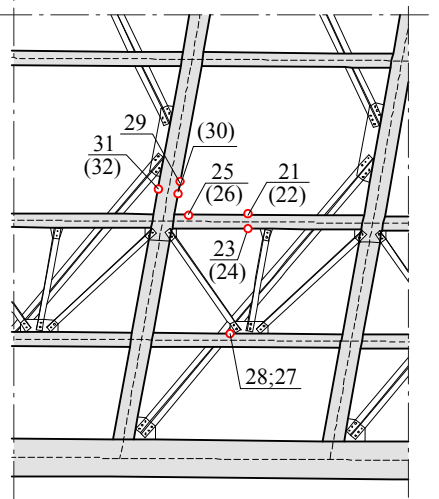

b)
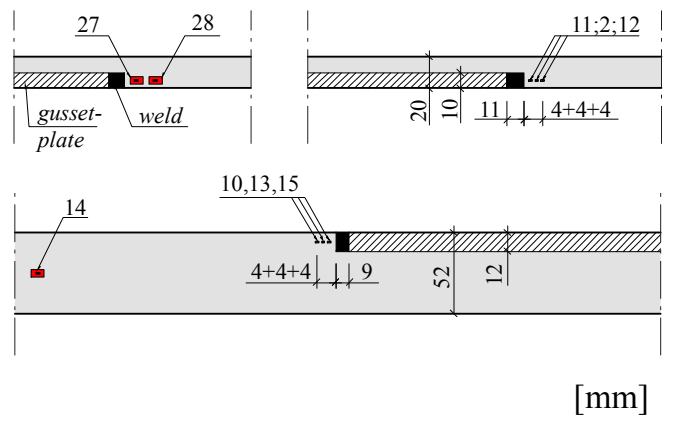

c)

Fig. 4: Instrumentation with strain gauges, after repositioning in 2011, a) plan view of the grillage, section I, b) section II, c) detailed sections for hotspot-measurements, numbers in parenthesis indicate gauges on lower flanges.

A HBM MGCPlus data acquisition system with 20bit effective resolution was used. Data was sampled at $400 \mathrm{~Hz}$ and collected with the CaTMan ${ }^{\circledR}$ software. Strain gauges with a length of $6 \mathrm{~mm}$ were used at positions measuring nominal stresses. For measuring stress concentrations, gauge set $11 ; 2 ; 12$, set $15 ; 13 ; 10$ and set $27 ; 28$ consist of $1.5 \mathrm{~mm}$ gauges pre-bundled at specified distances.

The measured strain from passing trains is dominated by the quasi-static response, with moderate influence of higher frequency dynamics. The resonant speed of moving vehicles can be calculated using Eq. (1), where $f_{0}$ is the natural frequency of the structure and $d$ the distance between axles. The maximum allowable speed is $80 \mathrm{~km} / \mathrm{h}$, corresponding to a load frequency of $8.5 \mathrm{~Hz}$ for an axle distance of $2.6 \mathrm{~m}$. To attenuate noise and electrical disturbances, the signals are subjected to a $15 \mathrm{~Hz}$ digital Butterworth low-pass filter prior to fatigue assessment.

$\nu=f_{0} \lambda, \quad \lambda=d / i, \quad i=1,2, \ldots$

\section{Fatigue assessment}

The fatigue assessment presented in this paper is based on Palmgren-Miners linear damage rule, [13], [12]. In Eq. (2), $n_{\mathrm{Ei}}$ is the number of stress cycles with a stress range $\Delta \sigma_{\mathrm{Ri}}$ and $N_{\mathrm{Ri}}$ is the maximum number of stress cycles until failure for a constant stress range. The stress collective is calculated using the Rainflow counting method in [15] and strain data from field measurements. The fatigue resistance follows the S-N curve described by Eq. (3), according to EN 1993-1-9 [2]. For $N>10^{8}$, the fatigue limit $\Delta \sigma_{\mathrm{L}}$ is used, $\Delta \sigma_{\mathrm{C}}$ denotes the reference fatigue strength at $N=2 \times 10^{6}$ cycles, determined by the detail category class. The measured stress is multiplied by the safety factor $\gamma_{M}=1.35$.

$D_{\mathrm{d}}=\sum_{i=1}^{n} \frac{n_{\mathrm{E} i}}{N_{\mathrm{R} i}}$

$\Delta \sigma_{\mathrm{R}}^{\mathrm{m}} N_{\mathrm{R}}=\Delta \sigma_{\mathrm{C}}^{\mathrm{m}} 2 \times 10^{6}, \quad m=3, N \leq 5 \times 10^{6}$

$\Delta \sigma_{\mathrm{R}}^{\mathrm{m}} N_{\mathrm{R}}=\Delta \sigma_{\mathrm{D}}^{\mathrm{m}} 5 \times 10^{6}, \quad m=5,5 \times 10^{6} \leq N \leq 10^{8}$

$\Delta \sigma_{\mathrm{D}}=0.4^{1 / 3} \Delta \sigma_{\mathrm{C}}, \Delta \sigma_{\mathrm{L}}=0.05^{1 / 5} \Delta \sigma_{\mathrm{D}}$ 


\subsection{Nominal stresses}

The connection between the beam flanges and the secondary bracing systems is identified as a transverse welded gusset plate, illustrated in Fig. 5. Corresponding detail categories $C_{\text {nom }}$ to be used for nominal stress ranges are given by Table 2. According to EN 1993-1-9, $C_{\text {nom }}$ for the present detail depends on the radius $r$ and plate width $w$, for no radius $C_{\text {nom }}=40$ is given. In [3] however, additional criteria related to the length $l$ of the gusset plate is provided. For the present study, $C_{\text {nom }}=$ 40 is used for all gusset plate connections.

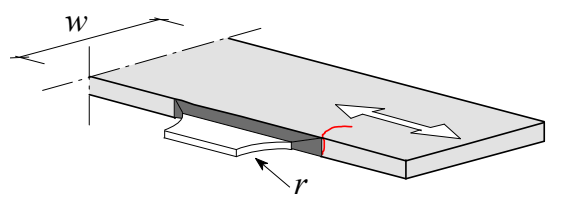

Table 2: Detail category for nominal stress, compiled from [2] and [3].

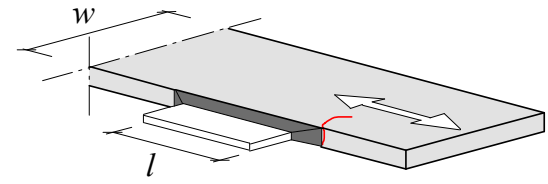

\begin{tabular}{lc}
\hline Geometry & $C_{\text {nom }}$ \\
\hline$r / w \geq 1 / 3$ or $r>150 \mathrm{~mm}$ & 90 \\
$1 / 6 \leq r / w \leq 1 / 3$ & 71 \\
$r / w<1 / 6$ & 50 \\
$r=0, l<150 \mathrm{~mm}$ & 50 \\
$r=0, l<300 \mathrm{~mm}$ & 45 \\
$r=0, l>300 \mathrm{~mm}$ & 40 \\
\hline
\end{tabular}

Fig. 5: Transverse gusset plate.

\subsection{Structural stresses}

Fatigue assessment based on local stresses is often used when no specific detail category is available. Recommendations and procedures are found in [3], both for numerical approaches and field measurements. Recent developments in the field of local approaches are also found in [14]. The structural stress, also known as geometrical or hotspot stress, describes the macrostructural behaviour excluding local notch effects. The structural stress is usually evaluated based on extrapolation of stresses at prescribed distances adjacent to the notch, usually the weld toe. In Fig. 6, the structural stress is obtained at point 5) based on a quadratic extrapolation of points 1) to 3). Optionally, a linear extrapolation using two points at different distances can be used. The real notch stress is obtained at point 6). For the notch-stress approach, an initial notch radius must be assumed to avoid a singularity at point 4 ).

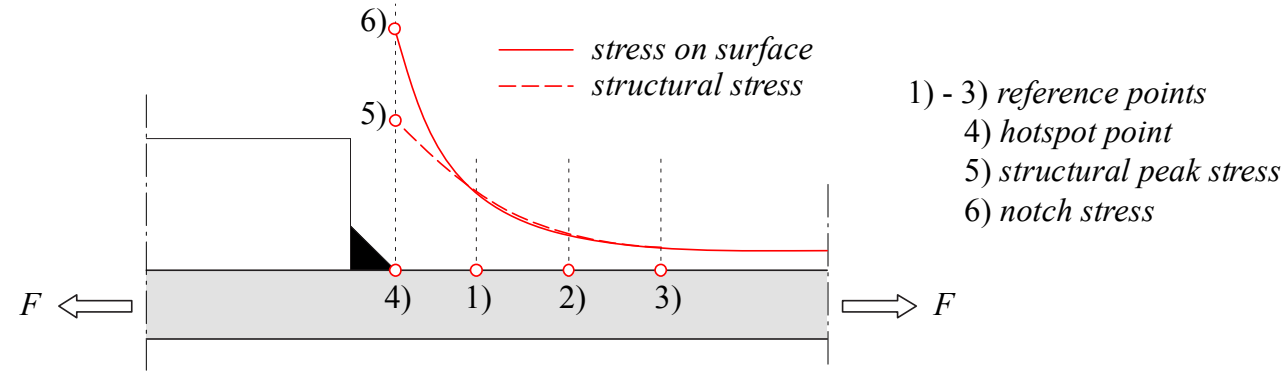

Fig. 6: Stress concentration at a transverse gusset plate, partly reproduced from [3].

For a "type b" hotspot according to [3], the hotspot stress is independent of the plate thickness and can be calculated directly; using quadratic extrapolation according to Eq. (4) or linear extrapolation using Eq. (5). The stress index refers to the distance from the weld toe. The resulting stress $\sigma_{\mathrm{hs}}$ shall be related to a detail category $C_{\mathrm{hs}}=100$ if $l \leq 100 \mathrm{~mm}$ or $C_{\mathrm{hs}}=90$ if $l>100 \mathrm{~mm}$.

$$
\begin{aligned}
& \sigma_{\mathrm{hs}}=3 \cdot \sigma_{4 \mathrm{~mm}}-3 \cdot \sigma_{8 \mathrm{~mm}}+\sigma_{12 \mathrm{~mm}} \\
& \sigma_{\mathrm{hs}}=1,5 \cdot \sigma_{5 \mathrm{~mm}}-0,5 \cdot \sigma_{15 \mathrm{~mm}}
\end{aligned}
$$




\subsection{Geometrical improvement of local members}

The fatigue strength of transverse gusset plates may be improved by increasing the transition radius. According to Table 2 however, a significant radius is needed which may not be possible for short gusset plates. Also, either of [2] or [3] accounts for different thickness of the loaded plate compared to the gusset plate. For the case study bridge, the gusset plates are $12 \mathrm{~mm}$ on the cross beam and $10 \mathrm{~mm}$ on the stringers. From Table 1, the flange thickness is $52 \mathrm{~mm}$ for the cross beam and $20 \mathrm{~mm}$ for the stringers. In [10] and [11], experiments on transverse gusset plates with radii of $20 \mathrm{~mm}$ to $50 \mathrm{~mm}$ was shown to improve the fatigue strength significantly.

The stress concentration at the connection between the flange and the gusset plate is studied using the FE-model shown in Fig. 7a). The model consists of tetrahedron elements with an element length of $1 \mathrm{~mm}$ in the vicinity of the weld and $0.2 \mathrm{~mm}$ at the weld toe. The notch stress concentration factor $K_{\mathrm{s}}$ at the weld toe is shown as function of the radius in Fig. $7 b$ ). The calculated notch stress factors were used in combination with a global FE-model of the bridge to estimate the change in fatigue service life due to different radii. These analyses are beyond the scope of the present paper, but resulted in a proposed radius of $20 \mathrm{~mm}$ for both the stringers and the cross beams.
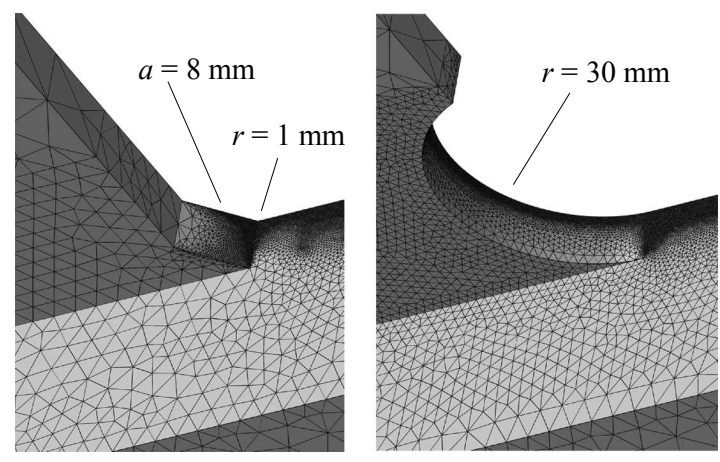

a)

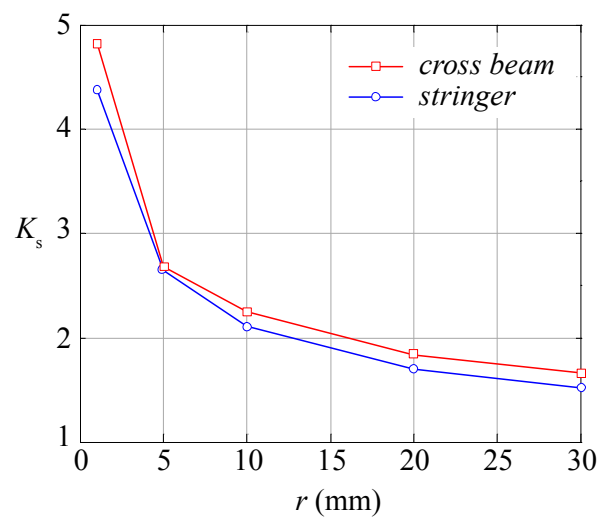

b)

Fig. 7: Stress concentrations evaluated based on FE-analysis, a) detailed model of the transverse bracing on the cross beam lower flange, b) resulting stress concentration factors at the weld toe as function of the radius $r$.

In 2011, the effect of the proposed geometrical improvement was tested on two positions; one at a stringer and one at a cross beam. Field measurements of hotspot stresses were performed before and after the improvement. Fig. 8 shows the geometry before and after improvement on the stringer, located at gauge $11 ; 2 ; 12$ according to Fig. 4 . The geometry of the weld prior to improvement was grinded to obtain a $45^{\circ}$ angle with the weld. The corresponding geometry of the cross beam is shown in Fig. 9, located at gauge position 15;13;10.

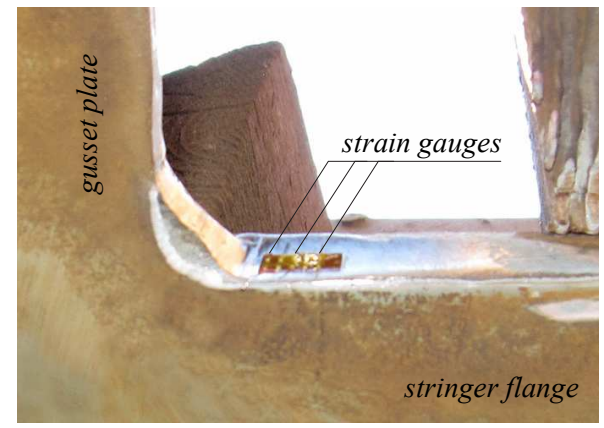

a)

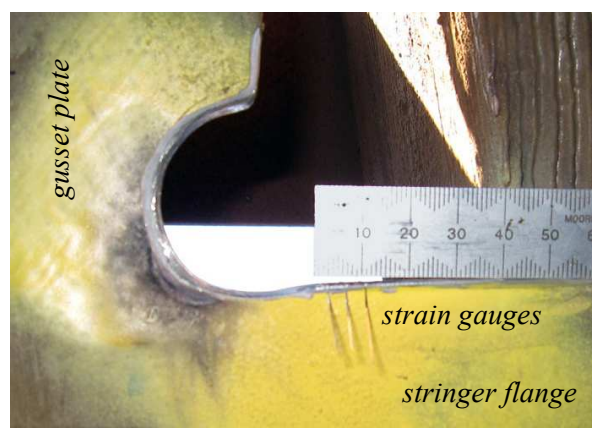

b)

Fig. 8: Stringer upper flange and gusset plate, a) instrumentation before geometry improvement, b) after geometry improvement, $20 \mathrm{~mm}$ radius. 


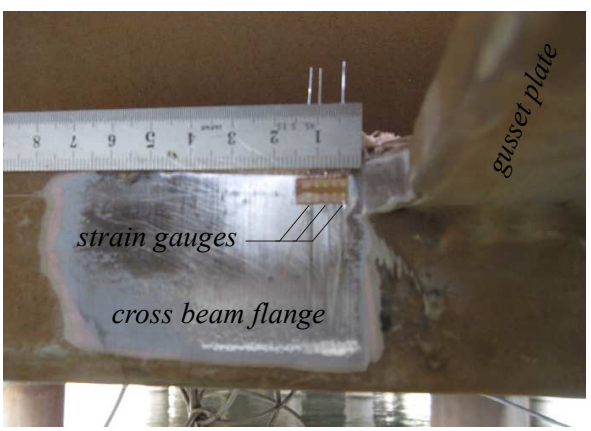

a)

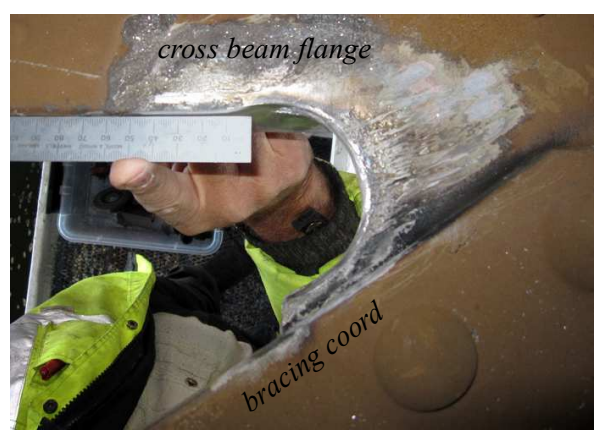

b)

Fig. 9: Cross-beam lower flange and gusset plate, a) instrumentation before geometry improvement, b) after geometry improvement, $20 \mathrm{~mm}$ radius.

\subsection{Cumulative damage based on field measurements}

Continuous measurements were performed during a five day period both before and after the geometrical improvement. In total, 2225 train passages were recorded before the improvement and 1721 train passages after the improvement. The raw data was stored in 30 min blocks by the data acquisition system. Each train record was later extracted from the raw data using routines developed in MATLAB [9]. Any incomplete train passages at the beginning or the end of each file was discarded and consequently not included in the fatigue assessment.

The stress collective calculated before and after the geometrical improvement is presented in Fig. 10. The stresses before improvement are calculated based on Eq. (4). After the improvement, there is no obvious position for extrapolation and the stress is instead calculated based on the mean value of all three strain gauges. A detail category $C=100$ is used after the improvement, corresponding to base material rather than hotspot stresses.

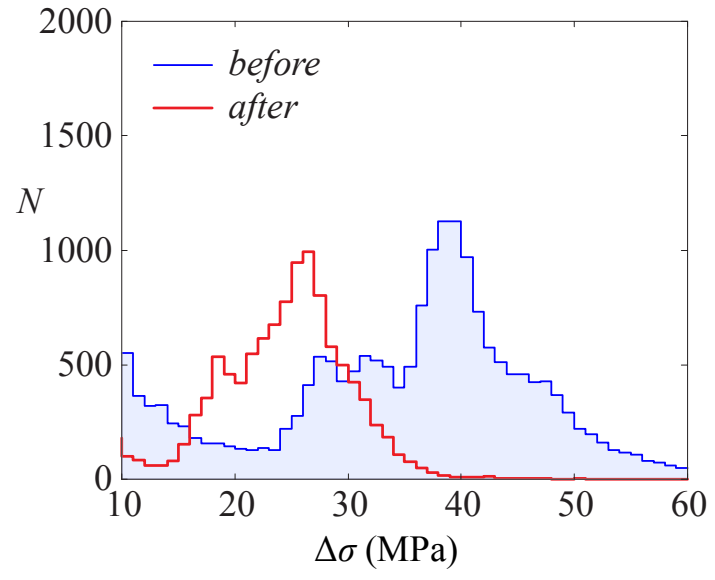

a)

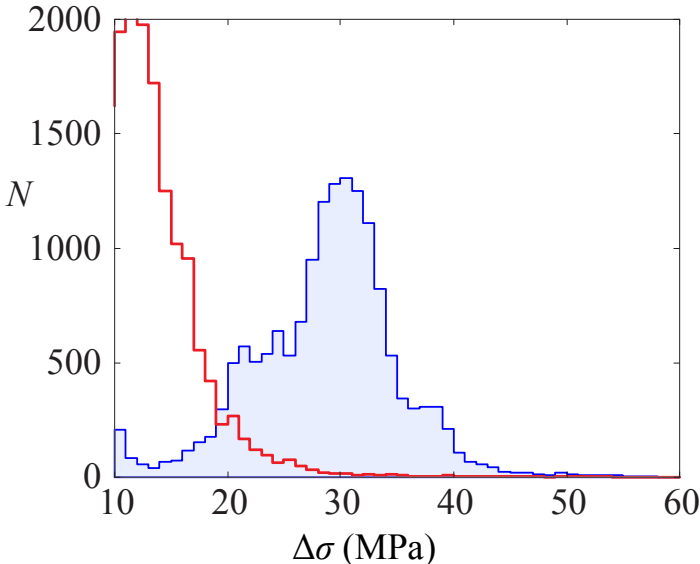

b)

Fig. 10: Stress collective based on measured strain before and after geometrical improvement, a) stringer, b) cross beam.

A total fatigue service life is estimated based on the cumulative damage from the above recorded train passages and assuming an average of 500 train passages per day. This does not account for any difference in load history occurring since the bridge was put in service and is rather to be seen as an equivalent of today's load intensity. The results for all available positions are presented in Table 3 . Only changes at the hotspot gauges are expected and any differences at other locations before and after the improvement are to be seen as uncertainties in the fatigue assessment. 
At the stringer, the service life based on nominal stresses ranges between $2-18$ years, in agreement with both significantly longer measurement periods [5]-[8] and numerical simulations of MonteCarlo seeded train data [1]. At the connection with the cross beam, gauge 25 and 26 does not indicate any risk of fatigue. Similar results are obtained from both periods of measurement, with the exception of gauge 3, showing higher fatigue service life on the adjacent side of the gusset plate. Discarding gauge 3, 25 and 26, the average service life is 7 years with an appertaining standard deviation of 4 years.

For the cross beam, nominal stresses show a service life in the range $24-89$ years. One exception is gauge 16 on the adjacent side of the gusset plate, which does not indicate any risk of fatigue. Discarding gauge 16, the average service life is 55 years with an appertaining standard deviation of 24 years. The large scatter in results may be due to partial stress concentrations at positions intended for nominal stress evaluation in combination with many stress cycles near the theoretical fatigue limit.

From the hotspot stresses, a significant increase in fatigue service life is found after the geometrical improvement. The same fatigue service life is obtained by using the hotspot stresses from gauge $11 ; 2 ; 12$ as from the nominal stress in gauge 1, both on the same stringer flange. Using a linear extrapolation of gage 27;28 does however result in a longer service life. It is not clear if this is due to the method of linear extrapolation or other inherent stresses at that position. The additional increase for the second measurement period may be related to similar effects as obtained for gauge 3. For the cross beam, the hotspot stresses results in a service life comparable to the lower range of the nominal stresses. After the improvement, both the stringer and the cross beam indicate that they are not prone to future fatigue damage.

Table 3: Estimated total service life in years, based on field measurements of 2225 train passages before geometrical improvement and 1721 train passages after improvement.

\begin{tabular}{|c|c|c|c|c|c|c|c|c|c|c|c|}
\hline \multicolumn{4}{|c|}{ stringer, nominal stress } & \multicolumn{4}{|c|}{ cross beam, nominal stress } & \multicolumn{4}{|c|}{ hotspot stress } \\
\hline sec. & ch: & before & after & sec. & ch: & before & after & sec. & ch: & before & after \\
\hline \multirow{4}{*}{ I } & 1 & 6 & 8 & \multirow{5}{*}{ I } & 4 & 55 & 60 & I & $11 ; 2 ; 12$ & 6 & $>100$ \\
\hline & 3 & 18 & 63 & & 14 & 32 & 45 & II & $27 ; 28$ & 40 & 98 \\
\hline & 5 & 5 & 7 & & 16 & $>100$ & $>100$ & I & $15 ; 13 ; 10$ & 19 & $>100$ \\
\hline & 7 & 14 & 14 & & 31 & 65 & 85 & & & & \\
\hline \multirow{6}{*}{ II } & 21 & 7 & 8 & & 32 & 24 & 24 & & & & \\
\hline & 22 & 11 & 11 & \multirow{4}{*}{ II } & 29 & 89 & 83 & & & & \\
\hline & 23 & 2 & 3 & & 30 & 73 & 48 & & & & \\
\hline & 24 & 3 & 3 & & 31 & 65 & 85 & & & & \\
\hline & 25 & $>100$ & $>100$ & & 32 & 24 & 24 & & & & \\
\hline & 26 & $>100$ & $>100$ & & & & & & & & \\
\hline
\end{tabular}

\section{Conclusions}

In this paper, the fatigue service life of a steel railway bridge has been investigated. Transverse gusset plates connecting the secondary bracing system to the flanges of the main load bearing system are found to be the most fatigue critical components. In total, more than 600 connections are found on the bridge. Based on field measurements, an insufficient fatigue service life was found for the stringers and cross beams. The results are in agreement with previous numerical simulations. The results are inflicted with large uncertainties, both due to stress ranges dominantly near the theoretical fatigue limit and due to stress concentrations related to an overall complicated structural behaviour. 
An improvement of the local geometry at the transverse gusset plate has been proposed and analysed by means of local stress approaches. A radius of $20 \mathrm{~mm}$ was cut out from the gusset plate on both a stringer and a cross beam. Field measurements before and after improving the geometry was performed. The results indicate that the improved geometry is not prone to future fatigue damage.

\section{Acknowledgements}

The field measurements presented herein were financed by the Swedish Transport Administration and is greatly acknowledged. The instrumentation was performed by KTH Structural Engineering and Bridges.

\section{References}

[1] ANDERSSON, A., "Fatigue assessment of railway bridges", Licentiate Thesis, Bulletin 96 (in Swedish), Royal Institute of Technology (KTH), Sweden, 2009.

[2] CEN, "Eurocode 3: Design of steel structures - Part 1-9: Fatigue”, EN 1993-1-9:2005, 2005.

[3] HOBBACHER, A., "Recommendations for fatigue design of welded joints and components", International Institute of Welding, IIW-XIII-2151-07/XV-1254-07, 2007.

[4] JRC, “Assessment of Existing Steel Structures: Recommendations for Estimation of Remaining Fatigue Life", JRC Scientific and Technical Reports, ISSN 1018-5593, 2008.

[5] LEANDER, J., “The Söderström Bridge, field measurements and fatigue assessment”. Report 126 (in Swedish), Royal Institute of Technology (KTH), Sweden, 2008.

[6] LEANDER, J., "Improving a bridge fatigue service life prediction by monitoring”, Licentiate Thesis, Bulletin 106, Royal Institute of Technology (KTH), Sweden, 2010.

[7] LEANDER, J., ANDERSSON, A., KAROUMI, R., "Enhanced Assessment of the Remaining Life of a Steel Railway Bridge", Key Engineering Materials, Vol. 413-414, p. 245-252, 2009.

[8] LEANDER, J., ANDERSSON, A., KAROUMI, R., "Monitoring and enhanced fatigue evaluation of a steel railway bridge", Engineering Structures, Vol. 32(3), p. 854-863, 2010.

[9] MATLAB, "MATLAB 2009b Reference manual", The MathWorks Inc, 2009.

[10] MIKI, C., "Retrofitting Engineering for Fatigue Damaged Steel Structures", International Institute of Welding, IIW-XIII-2284r1-09, 2010.

[11] MIKI, C., "Retrofitting Engineering for Steel Bridge Structures", International Institute of Welding, IIW-XIII-WG5-74-07, 2007.

[12] MINER, M.A., "Cumulative damage in fatigue", Journal of Applied Mechanics, Vol. 12(1), 1945.

[13] PALMGREN, A., “Die Lebensdauer von Kugellagern”, VDI Zeitschrift Vol. 68(14), 1924.

[14] RADAJ, D., SONSINO, C.M., FRICKE, W., "Recent developments in local concepts of fatigue assessment of welded joints", International Journal of Fatigue Vol. 31, p. 2-11, 2009.

[15] RYCHLIK, I., "A new definition of the rainflow cycle counting method", International Journal of Fatigue, Vol. 9(2), 1987. 